\title{
POTENCIJALNE MOGUĆNOSTI PRIMENE INTERNETA STVARI U OBRAZOVANJU
}

\author{
Duško Radaković1, \\ Dragan Cvetković2, \\ Zoran Radakovic ${ }^{3}$, \\ Srđan Stanojković \\ Srđan Trajković ${ }^{1}$
}

\author{
${ }^{1}$ Visoka škola strukovnih studija - \\ Beogradska politehnika, \\ Beograd, Srbija \\ 2Univerzitet Singidunum, \\ Beograd, Srbija \\ ${ }^{3}$ Mašinski fakultet, \\ Univerzitet u Beogradu, \\ Beograd, Srbija
}

\begin{abstract}
Rezime:
Tehnologija predstavlja samo jedan od mnogih problematičnih uticaja u obrazovanju. Živimo u eri u kojoj bogatstvo podataka i eksponencijalni rast u razvoju novih znanja predstavlja izazov za institucije da preispitaju podučavanje i učenje na globalnom tržištu. Pored toga, postoji potreba da se student pripremi za sve veću konkurenciju na radnom mestu. Sa novom tehnologijom kao katalizatorom, obrazovanje prelazi sa modela prenošenje znanja na model kolaboracije, aktivnosti, samostalnog usmeravanja i angažovanja, takav da pomogne studentima da povećaju svoje znanje i razviju veštine potrebne za uspeh u „društvu koje uči”. Razna istraživanja pokazuju da studenti uče tako što su aktivno angažovani u relevantnim i autentičnim aktivnostima, a tehnologija je ta koja ovo omogućava. Studenti takođe postaju sve veštiji u korišćenju društvenih mreža kao što su YouTube i Facebook, za razmenjivanje poruka, postavljanje videa, blogova ili slika, i za kolaboraciju i druženje bez obzira na vreme i mesto. Svakako, tu je i upotreba softverskih aplikacija za stvaranje ili interakciju sa sadržajem. Sve više učionica postaju „otvorene” putem videa, glasa ili tekstualnih poruka, dok se nastavnicima na raspolaganje stavlja široki opseg višemodalnih resursa za poboljšanje nastave. Pored sve savremenijeg shvatanja kako mozak funkcioniše i kako se učenje odvija, rešenja sa integrisanim tehnologijama, kao što su multimedija, igre i animacija, imaju značajnu ulogu u skraćivanju vremena za savladavanje i razumevanje nastavnog sadržaja. Sve više ljudi prihvata nove tehnologije za učenje, zbog čega će oni napredovati u svetu koji nastaje - u svetu Interneta svega, koji predstavlja mrežnu povezanost ljudi, procesa, podataka i objekata.
\end{abstract}

Ključne reči:

internet, obrazovanje, tehnologija, virtualna nastava.

\section{UVOD}

Internet stvari (engl. Internet of Things, IoT) predstavlja vezu raznovrsnih uređaja (različitih od standardnih proizvoda kao što su računari i pametni telefoni) i interneta. Ova veza dovodi do procesa transformacije brojnih oblasti u našem svakidašnjem životu. Možda ne izgleda kao očigledna primena, ali na listi IoT nalazi se i obrazovanje. Internet se duboko ukorenio u školama širom sveta, a e-learning postala je praksa u školama ra-

zvijenih zemalja (posebno u američkim školama). Međutim, primene IoT u

\section{Correspondence:}

Duško Radaković

e-mail:

dradakovic@politehnika.edu.rs 
obrazovanju su brojne, a posledice ovoga ogromne. Uspon mobilne tehnologije i IoT omogućava bolju bezbednost u školama, praćenje resursa i poboljšan pristup informacijama. Predavačima je omogućeno da koriste ovu tehnologiju radi kreiranja „pametnijih nastavnih planova”, umesto tradicionalnih, pasivnih.

Internet svega (engl. Internet of Everything, IoE) trebalo bi da bude naredni korak u evoluciji pametnih stvari, pri čemu je nejasna veza između fizičkih objekata i digitalne informacije o tom objektu [1]. Međutim, IoT se bavi samo senzorima mreže, što omogućava da mašine međusobno komuniciraju, pri čemu kao rezultat nastaje podatak.

\section{IoT u visokom obrazovanju}

Internet stvari počinje da narušava proces obrazovanja već u osnovnim školama. U razvijem zemljama već u predškolskom uzrastu, pa sve do kraja srednjeg obrazovanja. Međutim, najznačajniji efekti javljaju se u visokom obrazovanju. Studenti, najčešće u višim školama, sve više prelaze sa štampanih knjiga na tablete i laptopove. Uz svu dostupnu, potrebnu informaciju, studenti sada uče svojim tempom, a imaju gotovo identično iskustvo radeći od kuće ili u učionici. Sa jedne strane ovaj trend studentima omogućava više pogodnosti, sa druge strane proces učenja je efikasniji za profesore. Napredak u povezanosti tehnologije znači da nastavnici ne moraju ručno da pregledaju testove (pisane radove) ili da obavljaju druge rutinske zadatke. Umesto toga, nastavnici sada mogu da se fokusiraju na stvarnu, ličnu poduku koja je najznačajnija studentima. Uređaji povezani sa cloud-om omogućavaju profesorima da prikupe podatke o svojim studentima, a zatim da procene kome treba da posvete više pažnje. Ova statistika takođe omogućava profesorima da adekvatno pripreme plan nastave za buduće lekcije.

Izvan učionice, škole i univerziteti mogu da koriste povezane uređaje radi praćenja svojih studenata, zaposlenih, kao i resursa i opreme. Dramatičan pad cena za snagu procesiranja (procesori, CPU), skladištenja i opsega, sa jedne strane, kao i porast cloud-a, društvenih medija i mobilnih uređaja, daju mogućnost da se analiziraju veliki podaci i pretvore u svrsishodnu informaciju upravo omogućavajući ovakve primene. Ovakve mogućnosti praćenja trebalo bi da dovedu do bezbednijih okruženja. Na primer, studenti bi mogli da imaju uvid u satnice gradskog prevoza i prema tome organizuju svoje obaveze.

\section{PREGLED UPOTREBE MOBILNE I DEKSTOP PLATFORME}

Posmatrajući statističke podatke o upotrebi mobilnih uređaja, lako se može zaključiti kako će IoT radikalno transformisati obrazovanje kakvo nam je do sada poznato. Na Slici 1 prikazana je statistika korisnika mobilnih uređaja prema desktop uređajima u poslednjih desetak godina. Danas se sa sigurnošću može tvrditi da mobilne platforme dominiraju u internet tehnologijama.

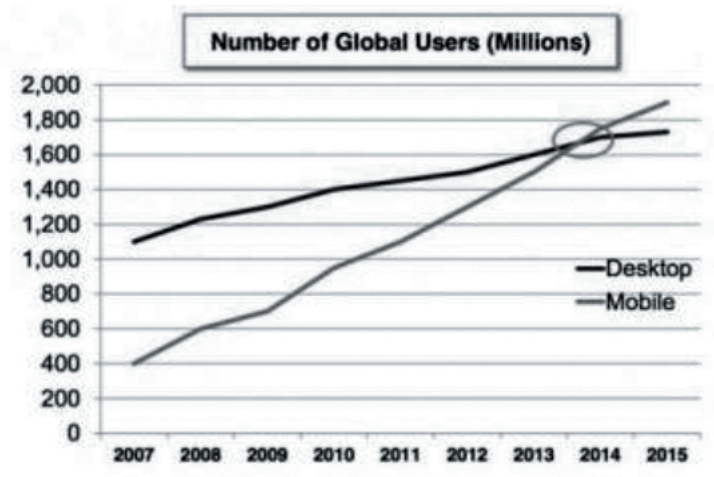

COMSCORE

Slika 1. Broj korisnika mobilne i desktop platforme.

Statistička obrada podataka obuhvatila je pitanja:

1. Vreme provedeno na internetu;

2. Broj korisnika koji koriste mobilne uređaje;

3. Broj poseta veb-sajtovima sa mobilnih u odnosu na desktop uređaje;

4. Odnos upotrebe mobilnih aplikacija prema mobilnim sajtovima.

\section{Vreme provedeno na internetu}

Broj korisnika mobilne tehnologije varira tokom dana. Ovo je značajno zbog mnogih elemenata, posebno marketinga i prikazivanja medije. Prema istraživanjima comScore Global Digital Future in Focus, desktop je i dalje važna platforma za dnevni rad i korisnike na poslu, dok u večernjim časovima dominiraju tableti i pametni telefoni (Slika 2).

Pored toga, takođe je bitan podatak koliko vremena se provede u pretraživanju podataka pomoću pametnih telefona (Slika 3).

Na Slici 4 prikazan je dijagram prosečne upotrebe di-gitalnih medija kod populacije odraslih osoba u SAD. 
Pod ostalim konektovanim uređajima obuhvaćeni su OTT (Over-The-Top content) i igračke konzole. Mobilnim uređajima obuhvaćeni su pametni telefoni i tableti. Prikazana upotreba odnosi se radnu i vanradnu sredinu.

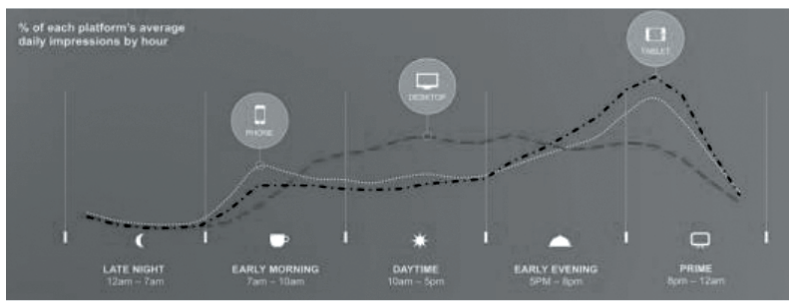

Slika 2. Procentualna zastupljenost upotrebe platforme tokom dana.

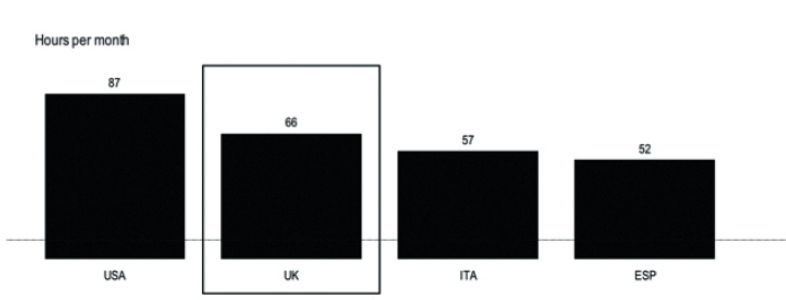

Slika 3. Prosečno vreme provedeno u pretraživanju na pametnim telefonima u avgustu 2016. Vreme korišćenja izraženo je u satima na mesečnom nivou [9].

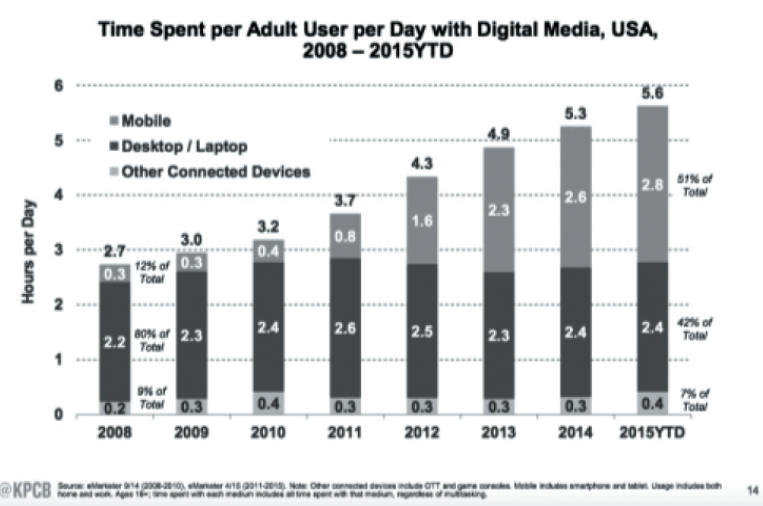

Slika 4. Prosečna upotreba digitalnih medija (izvor: eMarketer 9/14 (2008-2010), eMarketer 4/15 (2011-2015)) [8].

\section{Broj korisnika koji koriste mobilne uređaje}

Na Slici 5 prikazana je Ofcom-ova analiza popularnosti digitalnih uređaja u različitim zemljama.

Pored toga, analiza koju je sproveo comScore pokazuje da većina potrošača koristi „multiplatformu” (Slika 6), često istražuje i pristupa sajtovima i sa mobilnog i sa desktop uređaja. To znači da je potrebno imati na umu konzistentna iskustva na različitim uređajima.

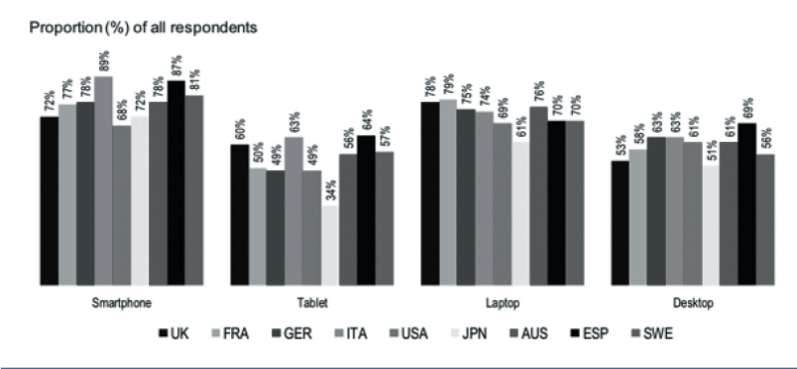

Slika 5. Broj korisnika komunikacione platforme u 2016. godini [6].

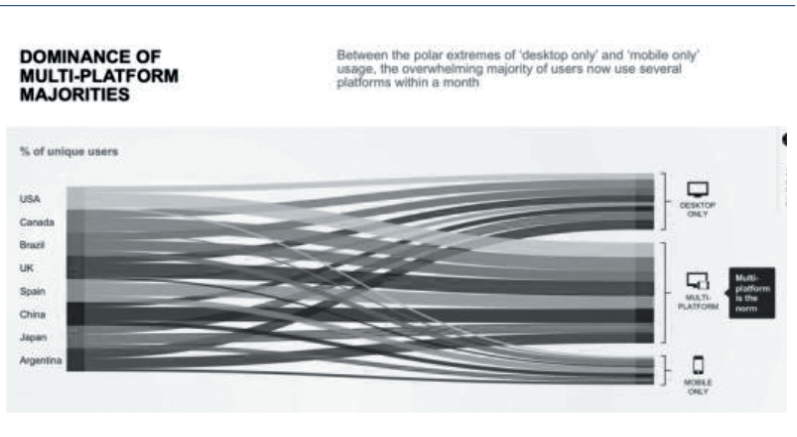

Slika 6. Statistika korišćenja različitih platformi u različitim zemljama.

Broj poseta veb-sajtovima sa mobilnih u odnosu na desktop uređaje

Svakako treba biti pažljiv pri interpretaciji podataka vezanih za provedene sate, jer se najviše vremena provodi na pametnim telefonima u proveri e-pošte i upotrebi društvenih medija. Ovo je i dovelo do čuvene „mantre” dizajniranja Mo-bile First. Ovaj pristup nije najbolje rešenje, što je u jednom intervjuu u vezi sa pristupom Mobile First potvrdio i predsed-nik Google-a, Eric Schmidt.

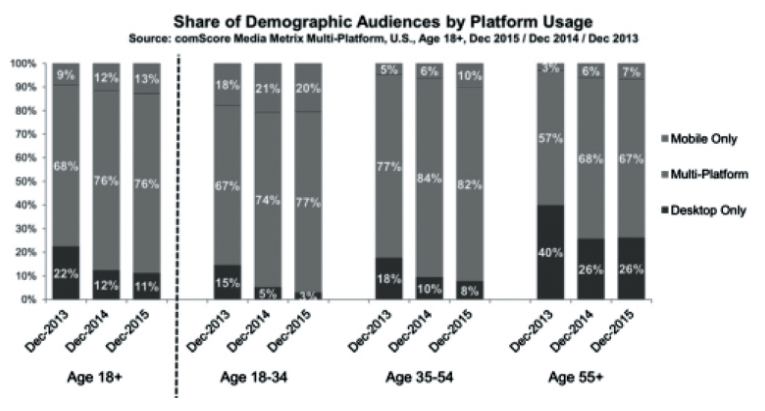

Slika 7. Starosna dob korisnika prema korišćenoj platformi. 
Stvarnost je takva da su pametni telefoni veoma popularni za neke aktivnosti (društvene medije, slanje poruke i praćenje vesti i tračeva), dok većina „zapadnih” korisnika ima i desktop uređaje (i tablet uređaje) koje koristi za detaljnije informacije i kupovinu. Shodno tome, potrebno je razmišljati o strategijama za uključivanje u multiplatformsku većinu. Ova kombinacija proističe iz različitih potreba korisnika, kao i zbog toga što su troškovi na mobilnim mrežama mnogo niži u maloprodaji, što pokazuje analiza saobraćaja između maloprodajnih sajtova koja je generalno ista za pametne telefone i desktop uređaje.

Odnos upotrebe mobilnih aplikacija prema mobilnim sajtovima

Korisnici radije biraju mobilne aplikacije umesto mobilnih veb-sajtova. Ovo bi trebalo posmatrati kao deo mobilne strategije. Danas, prema statistici Yahoo Flurry, gotovo 90\% vremena koje korisnici provedu na mobilnim uređajima, provedu koristeći aplikacije. Ovo je zaista značajan uvid jer prema ovome kompanije se radije odlučuju da kreiraju mobilnu aplikaciju ili aplikaciju specifičnu za mobilni uređaj. Prema godišnjem izveštaju „State of Mobile” vreme koje korisnici provedu koristeći mobilne aplikacije raste oko $70 \%$ iz godine u godinu. YouTube u svom izveštaju kaže da njihovi korisnici provedu milijardu sati dnevno gledajući video. $U$ Americi, korisnici u proseku provedu 5 sati dnevno uz svoje mobilne uređaje. Prema podacima Yahoo! Flurry, američki korisnici imaju tendenciju da provode još više vremena. Prema njima, u odnosu na 2015. godinu ovo je skok od 20\%. U ukupnoj upotrebi, upotreba pretraživača konstantno pada i trenutno iznosi jedva $8 \%$.

US Daily Mobile Time Spent

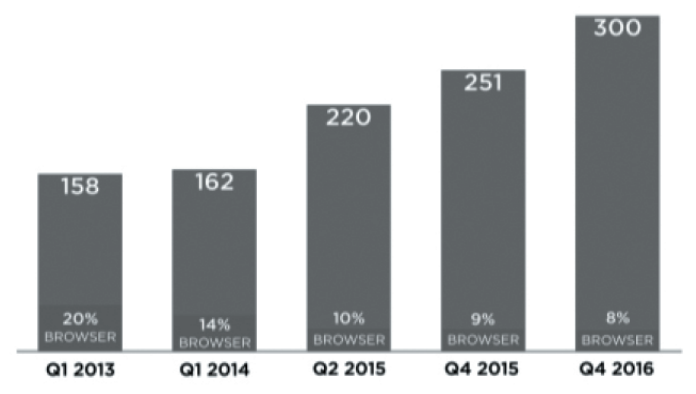

Slika 8. Vreme provedeno na mobilnom uređaju koristeći mobilne aplikacija i pretraživače (izraženo u minutima) [7].
Na Slici 9 može se uočiti da korisnici provedu 50\% vremena na društvenim mrežama, slanju poruka i aplikacijama zabave. Ovo se danas naziva komunitejnment (engl. communitainment=communication + entertainment). Snapchat je nova aplikacija upravo za komunitejnment (gotovo da će izgurati Viber sa tržišta), koju danas koristi $60 \%$ Amerikanaca sa $2 \%$ ukupnog dnevnog vremena. Facebook, Instagram i Whatsapp još uvek drže najveći deo vremena, posebno pošto je sada objavljen Facebook Live i Instagram Stories. Aplikacija YouTube zastupljena je 3\% ukupnog provedenog vremena. Međutim, nezavisne Entertainment aplikacije su značajno pale, tako da je udeo od 14\% zapravo sadržaj koji je migrirao na Youtube, Facebook i Snapchat. Ključni podatak od 92\% je smernica kompanijama za odlučivanje da li razvijati mobilne aplikacije ili se ograničiti na sajtove optimizovane za mobilne uređaje.

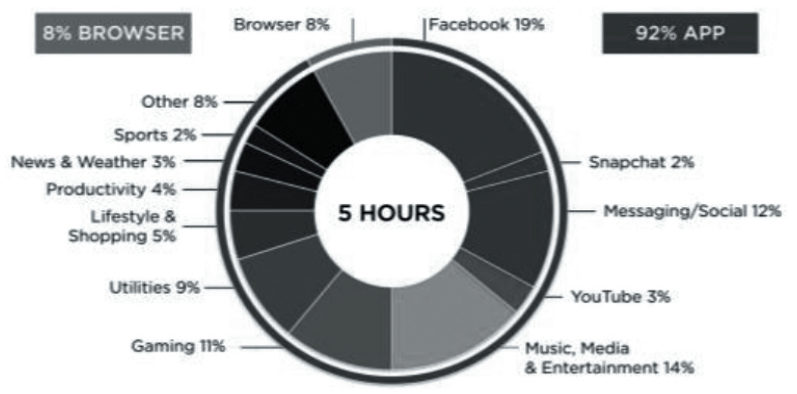

Slika 9. Korišćenje aplikacija u ukupnom vremenu provedenom na Internetu [7].

\section{BUDUĆNOST INTERNETA U OBRAZOVANJU}

Posmatrajući stanje u zemljama visokog standarda u tehno $\neg$ logiji i obrazovanju, preko $70 \%$ tinejdžera ima pristup pamet $\neg$ nom telefonu. Gotovo da sve škole imaju pristup internetu, a blizu 75\% studenata visokih škola koriste laptopove u eduka $\neg$ tivne svrhe. Prema svemu ovome (i prethodnoj statistici), jasno je da će IoT značajno promeniti obrazovanje kakvo da $\neg$ nas poznajemo. Po istraživanjima Capterra, oko $70 \%$ stude $\neg$ nata ima želju da koristi svoj mobilni uređaj češće u učionici, tokom nastave, a većina njih dodatno želi da ih koristi za auᄀtomatizaciju zadataka, kao što je hvatanje beleški, provera rasporeda i istraživanje. Što se škola tiče, naviše koristi bi bilo u efikasnijoj uštedi energije i smanjenje operativnih troškova. Korišćenjem veb baziranih sistema koji kontrolišu svu meha $\neg$ ničku opremu unutar 
objekata mogu se uštedeti značajna sred $\neg$ stva. Tako, na primer, škola New Richmond iz Ohaja godišnje uštedi oko 120000 dolara [2]. Prema nekim autorima (Green $\neg$ tech Media) investicija u pametne škole najčešće se isplati već posle par godina. Ova tehnologija može da se instalira i u sta $\neg$ rijim zgradama dodavanjem senzora i drugih uređaja na posto $\neg$ jeće kontrolne panele. Ušteda na ovaj način omogućava druge investicije - računari, tableti, pametni telefoni.

IoT ima ogroman potencijal u obrazovanju. Međutim, za uspešnu implementaciju potrebno je pozabaviti se:

1. Zaštitom;

2. Integritetom podataka;

3. Obrazovnom politikom.

Bezbednost je veliki problem na svim tržištima, a posebno u obrazovanju. Bez bezbednosti, integrisani razvoj IoT neće biti moguć kroz obrazovne institucije. Informacije treba da budu dostupne, ali kada je potrebno i poverljive. Vlasnik informacije je taj koji će odlučivati o tome kome obezbediti pristup informacijama. Za niže obrazovanje se već nagoveštava pitanje: da li je bezbednost u domenu učenika (maloletnici) ili obrazovne ustanove? Sa koliko godina starosti učenik može da upravlja sa svojim ličnim podacima? $\mathrm{Na}$ ovo se nadovezuje i to u kojoj meri će zaštita uticati na mogućnost da se odluke donose na osnovu podataka. Prema ovome, neminovno se dolazi do složenih mreža ljudi i stvari u javnom i privatnom sektoru. Takvi uređaji će verovatno stvarati nove veze između ljudi i računara. Potrebno je uskladiti i uravnotežiti pozitivne strane vezane za IoT i rizike po pitanju privatnosti i bezbednosti. Nastavnici i učenici moraju da imaju bolju predstavu o etičkim pitanjima i rizicima koje nosi IoT, kao i kako da se isti smanje. Lični i opšti podaci moraju da se obrađuju na različite načine jer je potrebno ispoštovati privatnost pojedinca.

Druga stvar, integritet podataka takođe mora da se ispoštuje, kao i tačnost, autentičnost, potpunost i rokovi. Uspeh se zasniva na otvorenoj platformi koja bi omogućila da svi učesnici zajedno rade na istim baznim tehnologijama. Ministarstvo i nastavnici morali bi da sarađuju kako bi se osigurao razvoj IoT u obrazovanju. Istovremeno, Vlada i Ministarstvo treba da obezbede bezbednost i zaštitu svojih građana.

Veoma su značajne politike obrazovanja koje podstiču prihvatanje tehnologije i učionicama i njeno efektivno integrisanje u kurikulume predmeta. Za ovo je potrebna zdrava praksa upravljanja promenama u obrazovnim institucijama, jer to omogućava da se smanje prepreke za prihvatanje tehnologije i proširivanje njene primene. Za predavače je potrebno definisati edukativne programe sa
IoT alatima koji bi podstakli lakše prihvatanje i pomoć za razvijanje novih metodologija i adekvatnih pedagogija za obrazovno okruženje.

\section{ZAKLJUČAK}

Autori ovog rada imali su nameru da prikažu zastupljenost interneta u svakodnevnom životu, kao i to da se povezivanjem uređaja i stvari preko inteligentnih mreža u obrazovanju može stvoriti veliki napredak u obrazovanju. Takođe, nagoveštava se i potencijal IoT tako što je moguće značajnije uključiti i motivisati studente/ učenike u procesu obrazovanja. Međutim, da bi sve ovo funkcionisalo i dalo korisne rezultate, potrebno je obezbediti konstantnu povezanost i dostupnost. Pored toga, predavači, obrazovne institucije i ministarstva moraju da kvalitetno pripreme teren za ovakvu primenu tehnologije u obrazovanju, ali i da znaju koji su potencijalni rizici ovakve primene.

\section{LITERATURA}

[1] Kevin Ashton, „That 'Internet of Things' Thing: In the Real World, Things Matter More than Ideas", RFiD Journal, 22.07.2009., (http://www.rfidjournal. com/articles/view?4986)

[2] Andrew Meola, „How IoT in education is changing the way we learn", Bussiness Insider, 2016., (http:// www.businessinsider.com/internet-of-things-education-2016-9)

[3] Jeanette Cajide, „The Connected School: How IoT Could Impact Education", The Huffington Post, 2016. (http://www.huffingtonpost. com/jeanettecajide/the-connected-school-how-_b_8521612. html)

[4] Dave Chaffey, „Mobile Marketing Statistics compilation", mart 2017., http://www.smartinsights.com/ mobile-marketing/

[5] Internationa Telecommunications Union, „ICT Facts and Figures 2016", http://www.itu.int/en/ITUD/Statistics/Pages/stat/default.aspx

[6] Ofcom Consumer Research, „Internet use and attitudes", oktobar 2016, https://www.ofcom.org.uk/ research-and-data/cmr/cmr16

[7] Simon Khalaf, Lali Kesiraju, „The Media Industry: Absorbed by Apps", Decembar 2016, Yahoo! Flurry Analytics Blog, http://flurrymobile. tumblr.com/ post/127638842745/seven-years-into-the-mobilerevolution-content-is

[8] Mary Meeker, „Internet Trends 2016 - Code Conference“, Kleiner Perkins Caufield \& Byers, June 1 2016, http://www.kpcb.com/internet-trends 
[9] D. Chaffey, „Mobile Marketing Statistics“, comScore Inc. Mobile Metrix, februar 2017.
[10] Cliff Saran, „Internet of things to power classroom education", Computer Weekly, 2013, http://www. computerweekly.com/news/22402 03884/Internetof-things-to-power-classroom-education

\section{POTENTIALS OF THE INTERNET OF THINGS IN EDUCATION}

\begin{abstract}
:
Today's technology presents just another problematic influence in education. The era we live in is enriched with data and exponential growth in developing new knowledge. This is a challenge for many institutions to question the teaching and learning methods employed in their educational process. As a direct effect, this advance in technology also creates a need to improve workers' competencies in the workplace. Having this Technology Enhanced Learning (TEL) methodology, education is changing the way knowledge is gained. It is moving to a collaborative, active, self-directed and engaging model that should help students increase their knowledge and develop skills in order to succeed in a learning society. Research shows that stu $\neg$ dents learn by being actively engaged in relevant and authentic activi $\neg$ ties, which is enhanced by technology. They also become more skilled in using social networks (e.g. YouTube, Facebook) for mes $\neg$ saging, uploading videos, blogs, images, but for collaboration and socializing as well. Use of software applications enables them to create or interact content. Classrooms are becoming more "open" thanks to video, voice or text messaging. On the other hand, teachers have at their disposal a wider range of resources to enhance teaching. As we are aware of how the brains works and how learning is done, solutions that integrate TEL (e.g. multimedia, games, animations, etc.) have an important role in shortening the time to master learning content. More and more people are adopting new technologies for learning. Eventually, they will succeed in the world of Internet of Everything, which is representing a networked connection between people, processes, data and objects.
\end{abstract}

\section{Keywords:}

internet, education, technology, virtual learning. 